\title{
A Genetic Screen for Mutations That Affect Cranial Nerve Development in the Mouse
}

\author{
Lynn Mar, ${ }^{1}$ Elena Rivkin, ${ }^{1,2}$ Dennis Y. Kim, ${ }^{1,2}$ Joanna Y. Yu, ${ }^{1,2}$ and Sabine P. Cordes ${ }^{1,2}$ \\ ${ }^{1}$ Samuel Lunenfeld Research Institute, Mount Sinai Hospital, Toronto, Ontario, Canada M5G 1X5, and 2Department of Medical and Molecular Genetics and \\ Microbiology, University of Toronto, Toronto, Ontario, Canada M5S 1A8
}

Cranial motor and sensory nerves arise stereotypically in the embryonic hindbrain, act as sensitive indicators of general and regionspecific neuronal development, and are directly or indirectly affected in many human disorders, particularly craniofacial syndromes. The molecular genetic hierarchies that regulate cranial nerve development are mostly unknown. Here, we describe the first mouse genetic screen that has used direct immunohistochemical visualization methods to systematically identify genetic loci required for cranial nerve development. After screening 40 pedigrees, we recovered seven new neurodevelopmental mutations. Two mutations model human genetic syndromes. Mutation 7-1 causes facial nerve anomalies and a reduced lower jaw, and is located in a region of conserved synteny with an interval associated with the micrognathia and mental retardation of human cri-du-chat syndrome. Mutation $22-1$ is in the Pax 3 gene and, thus, models human Waardenburg syndrome. Three mutations cause global axon guidance deficits: one interferes with initial motor axon extension from the neural tube, another causes overall axon defasciculation, and the third affects general choice point selection. Another two mutations affect the oculomotor nerve specifically. Oculomotor nerve development, which is disrupted by six mutations, appears particularly sensitive to genetic perturbations. Phenotypic comparisons of these mutants identifies a "transition zone" that oculomotor axons enter after initial outgrowth and in which new factors govern additional progress. The number of interesting neurodevelopmental mutants revealed by this small-scale screen underscores the promise of similar focused genetic screens to contribute significantly to our understanding of cranial nerve development and human craniofacial syndromes.

Keywords: cranial nerve; mutations; mice; axon guidance; brain development; genetics; sensory neurons; neural tube; neural crest; neural plate; nerve; motor neuron; development

\section{Introduction}

The nerves that innervate the vertebrate head, throat, and heart arise stereotypically in the embryonic hindbrain and are affected by many human craniofacial syndromes (Cordes, 2001; Wilkie and Morriss-Kay, 2001). During early embryogenesis, each cranial sensory and motor nerve can be easily recognized by its origin, pathway, and target. Thus, examination of hindbrain neurodevelopment provides a path toward understanding both general and region-specific neurobiologic mechanisms. The embryonic hindbrain is transiently subdivided into seven to eight segments, the rhombomeres ( $\mathrm{r} 1-\mathrm{r} 8)$, along its anterior-posterior axis (Lumsden and Keynes, 1989). Cranial motor nerves arise within specific rhombomeres (as shown in supplemental Fig. 1, available at www.jneurosci.org as supplemental material) and can be subdivided into two general classes: the ventral motor nerves (vMNs) and the dorsal motor nerves (dMNs). Axons of vMNs have ventral exit

Received April 4, 2005; revised Nov. 10, 2005; accepted Nov. 14, 2005.

This work was funded by an EJLB Foundation Scholar Award to S.P.C., by a generous gift from Mr. Henry Bernick and Mrs. Esther Bernick, and by Grant 14312 from the Canadian Institute for Health Research. We thank Monica Justice for advice regarding mutagenesis of $557 \mathrm{BL} / 6 \mathrm{~J}$ mice, Joe Culotti for critical reading of this manuscript, Lucy Osborne and the Canadian Models for Human Disease genotyping core for initial determination of genetic map positions, Dragana Vukasovic for secretarial assistance, Karin Weiss and Igor Vukabradovic for help with animal husbandry, and Timur Urakov for help with 26-1 mutant analysis.

Correspondence should be addressed to Sabine P. Cordes, Samuel Lunenfeld Research Institute, Room 865, Mount Sinai Hospital, 600 University Avenue, Toronto, 0N, Canada M5G 1X5. E-mail: cordes@mshri.on.ca.

DOI:10.1523/JNEUROSCI.3813-05.2005

Copyright $\odot 2005$ Society for Neuroscience 0270-6474/05/2511787-09\$15.00/0 points just like somatic motor neurons of the spinal cord. All other cranial motor neurons belong to the $\mathrm{dMN}$ class and project axons dorsally out of the neural tube. Sensory components of cranial ganglia arise from placodes or from neural crest cells. The distinctive appearance of cranial sensory and motor nerve processes provides a unique tool for studying the mechanisms that control vertebrate neurodevelopment and axon guidance.

Analyses of mouse mutants have begun to identify molecules required for specification and pathfinding of cranial nerves (Cordes, 2001). These insights have been gained either by fortuitous observations of cranial nerve anomalies in knock-out or classical mouse mutants or by deliberate pairing of gene expression analyses with reverse genetics. In the latter approach, molecules expressed in neuronal subsets are identified and the consequences of their loss and gain of function analyzed in the mouse and chick (Tsuchida et al., 1994; Lin et al., 1998; Briscoe et al., 2000; Liu et al., 2001). Pairing expression-based analyses directly with embryonic stem cell-based "genetrap" approaches has expedited progress further (Leighton et al., 2001; Mitchell et al., 2001). Most often, reverse genetic approaches have focused on molecules with previously known neurobiological roles in invertebrates. To identify molecules with previously unknown neurobiologic roles or less incriminating expression patterns, a forward genetic screen that systematically recovers mutations affecting cranial nerve development in the mouse should prove invaluable.

The potent mutagen $N$-ethyl- $N$-nitrosourea (ENU) and avail- 
ability of the mouse genome sequence have made forward genetic screens and identification of the affected gene(s) highly feasible in the mouse (Takahashi et al., 1994; Cordes, 2005). Once treated with ENU, a single male mouse can produce 100-150 progeny $\left(G_{1}\right.$, "first generation"), each of which represents one mutagenized gamete. On average, the high efficiency of ENU mutagenesis results in a new mutation in any single locus in one of $500-1000 G_{1}$ animals. To screen for recessive mutations, each $G_{1}$ male is used to create a three-generation pedigree, in which he is mated with three to six of his daughters $\left(\mathrm{G}_{2}\right.$ females) (supplemental Fig. 2, available at www.jneurosci.org as supplemental material). This approach has led to the recovery of mutations affecting processes ranging from sonic hedgehog signaling and telencephalic development to neonatal viability (Kasarskis et al., 1998; Zoltewicz et al., 1999; Anderson, 2000; Eggenschwiler et al., 2001; Herron et al., 2002; Garcia-Garcia and Anderson, 2003). Here, we have used ENU mutagenesis to generate and an immunohistochemical assay that stains neuronal processes to identify recessive mutations that affect cranial nerve development. We recovered mutations affecting processes ranging from global axon outgrowth to region-specific axon guidance. Even before identification of the causative genes, phenotypic comparison among mutants revealed that axon guidance of the oculomotor nerve is particularly sensitive to genetic perturbations. Finally, two of the mutants model known human genetic syndromes and, therefore, promise to provide novel insights into their etiology and treatment.

\section{Materials and Methods}

Mutagenesis and establishment of mouse strains. Twenty-five 8- to 10week-old C57BL/6J male mice were treated with three weekly fractionated doses of $85 \mathrm{mg} / \mathrm{kg}$ ethyl- $N$-nitrosourea. Ten weeks after their final ENU treatment, male mice had regained their fertility and were bred to normal C57BL/6J females. In these experiments, no more than five $G_{1}$ males were derived from the same $G_{0}$ ENU-treated male. To generate pedigrees from 40 of the resulting $G_{1}$ progeny males, each $G_{1}$ male was bred to two normal C57BL/6J females and subsequently was bred with five to seven of his resulting $G_{2}$ daughters. $G_{3}$ embryos were harvested at 10.5 days postcoitus $(\mathrm{dpc})$, and stained with anti-neurofilament antibody as described below. A $\mathrm{G}_{1}$ male was considered to carry a neurodevelopmental mutation if the identical phenotype was observed in multiple progeny from the same litter and in multiple progeny from other independent litters. To generate strains from $G_{1}$ carrier males, the $G_{1}$ male was bred to both $\mathrm{C} 57 \mathrm{BL} / 6 \mathrm{~J}$ females for strain maintenance and potential behavioral analyses and to $\mathrm{C} 3 \mathrm{H} / \mathrm{HeJ}$ females for genetic mapping studies. Carrier C57/C3H hybrid males were identified by breeding.

Immunohistochemical staining of embryos. Immunohistochemical staining protocol was adapted from that described by Mark et al. (1993). The 10.5 dpc embryos were collected in PBS, fixed overnight in $4 \%$ paraformaldehyde in $\mathrm{PBS}$ at $4^{\circ} \mathrm{C}$, washed three times in PBS containing $0.1 \%$ Tween-20 (PBT), and dehydrated with successive 15 min washes in $25,50,75 \% \mathrm{MeOH} / \mathrm{PBT}$, and two washes of $100 \% \mathrm{MeOH}$. Litters were stored at $-20^{\circ} \mathrm{C}$ until $20-50$ litters had been collected and could be processed simultaneously. To block endogenous peroxidases, embryos were treated with a 4:1:1 MeOH:DMSO: $\mathrm{H}_{2} \mathrm{O}_{2}$ solution for 5-6 h at room temperature. Thereafter, the embryos were rehydrated in successive 15 min washes of $75,50,25 \% \mathrm{MeOH}$, and $\mathrm{PBT}$ at room temperature. To allow for better antibody penetration, the telencephalon was punctured. The $10.5 \mathrm{dpc}$ embryos were treated with $10 \mu \mathrm{g} / \mathrm{ml}$ proteinase K (Sigma, St. Louis, MO) in PBT for 10-12 min at room temperature, and washed twice with freshly prepared PBT containing $2 \mathrm{mg} / \mathrm{ml}$ glycine. The embryos were refixed with fresh $0.2 \%$ glutaraldehyde $/ 4 \%$ paraformaldehyde in PBT for $20 \mathrm{~min}$ and washed three times with PBT. Nonspecific antibody binding was blocked by washing the embryos in PBSMT (PBS plus $0.1 \%$ Triton plus $2 \%$ skim milk) for $1 \mathrm{~h}$ each at room temperature twice and a subsequent incubation of the embryos in 5\% "secondary" sera for $2 \mathrm{~h}$ to overnight at $4^{\circ} \mathrm{C}$ in PBSMT. Embryos were incubated in a 1:1000 dilution of ascites containing $2 \mathrm{H} 3$ anti-neurofilament antibody (a monoclonal antibody raised against the $165 \mathrm{kDa}$ neurofilament subunit and obtained from the Developmental Studies Hybridoma Bank, Iowa City, IA) (Dodd et al., 1988) in PBSMT at $4^{\circ} \mathrm{C}$ for $12-24 \mathrm{~h}$ with gentle rocking. After three rinses with PBSMT, the embryos were washed five times in PBSMT at $4^{\circ} \mathrm{C}$ for $1 \mathrm{~h}$ each. Thereafter, the embryos were incubated in PBSMT plus 5\% goat serum for $1 \mathrm{~h}$. To reduce background, the secondary antibody was preabsorbed by incubating $50 \mu \mathrm{l}$ of goat antimouse secondary antibody (Vectastain) with $0.5 \mathrm{ml}$ of PBSMT, $5 \%$ goat serum, and $3 \mathrm{mg} / \mathrm{ml}$ embryo powder for each $10 \mathrm{ml}$ final antibody solution that was used for $2-6 \mathrm{~h}$ at $4^{\circ} \mathrm{C}$. After centrifugation, the antibodycontaining supernatant was further diluted to a final dilution of 1:200 of the original goat anti-mouse antibody. Embryos were incubated in PBSMT plus 5\% goat serum for $1 \mathrm{~h}$ and were then incubated overnight at $4^{\circ} \mathrm{C}$ with the secondary antibody diluted in PBSMT. After three rinses with PBSMT, the embryos were washed five times in PBSMT at $4^{\circ} \mathrm{C}$ for $1 \mathrm{~h}$ each. Peroxidase staining was developed according to the Vectastain protocol (Vector Laboratories, Burlingame, CA). In a few instances, embryos were dehydrated through a methanol series and cleared in benzyl alcohol:benzyl benzoate (1:2).

Genetic mapping of recessive mutations. The genetic map position of mutations was determined by analysis of segregation of chromosomespecific markers on $\mathrm{C} 3 \mathrm{H}$ inter-subspecific intercross panels by standard procedures. For the mapping of a recessive mutation, the progenitor $\left(\mathrm{G}_{1}\right)$ male was bred to $\mathrm{C} 3 \mathrm{H} / \mathrm{HeJ}$ females. Five of the resulting $\mathrm{G}_{2} \mathrm{C} 57 / \mathrm{C} 3 \mathrm{H}$ males were mated to three to four of their $G_{2}$ sisters, and progeny was tested to identify "carrier" males, which were heterozygous for the mutation. The $10.5 \mathrm{dpc}$ embryos were scored for the mutant phenotype by whole-mount immunohistochemistry with anti-neurofilament antibody. DNA was generated from all embryos from litters containing two or more embryos with the expected mutant phenotype. In previous studies, 45 of such DNA samples were genotyped for 70 MIT markers that show distinct $\mathrm{C} 57 \mathrm{BL} / 6 \mathrm{~J}$ and $\mathrm{C} 3 \mathrm{H} / \mathrm{HeJ}$ specific variations (Kasarskis et al., 1998). Markers located near the mutation should show homozygosity for the C57-specific variant in mutant animals and be either homozygous for the $\mathrm{C} 3 \mathrm{H}$ variant or heterozygous for the $\mathrm{C} 3 \mathrm{H}$ and $\mathrm{C} 57$ variants in unaffected animals. We found that, in some instances, we could obtain an initial approximate genetic map position with fewer DNA samples. After determining the penetrance of a given mutation, as shown in supplemental Table 1 (available at www.jneurosci.org as supplemental material), we focused, if possible, on collecting affected embryos for the purposes of genotyping. Thus, for the 22-1 and 25-3 mutations, we initially genotyped 20 affected animals. For 26-1, 6 affected and 39 unaffected animals were genotyped. For the 7-1 mutation, a total of 12 affected and 33 unaffected animals were initially genotyped. In the text, megabase positions of markers are given according to the assembly 32 from the ENSEMBL database. The flanking markers for these mutations are as follows: D15MIT130 7-1-D15MIT138; D1MIT132-22-1-D1MIT136; D9MIT121-26-1telomere; and D4MIT162-25-3-D4MIT136. We have confirmed linkage, in all instances, by additional analyses of at least an additional 20 intercross progeny.

\section{Results \\ Genetic screen design}

To identify recessive neurodevelopmental mutations, we screened third-generation $\left(\mathrm{G}_{3}\right)$ progeny from mutagenized C57BL/6J male mice using whole-mount immunohistochemistry with the $2 \mathrm{H} 3$ anti-neurofilament antibody. We performed these immunohistochemical analyses on $10.5 \mathrm{dpc} \mathrm{G}_{3}$ embryos for several important developmental and technical reasons: First, the antibody penetrates the embryonic tissues well at this stage, and, thus, neurons and axonal processes can be detected in their stereotypic positions allowing early innervation processes to be observed. Second, in contrast to 8.5-9.5 dpc timed matings, the variation in $10.5 \mathrm{dpc}$ embryonic staging is minimal, and embryos can be harvested with ease. Third, embryos with more severe patterning defects often can survive up to $10.5 \mathrm{dpc}$, and thus 
mutations that affect overall neural patterning are still recoverable. Fourth, some genetic effects on axon migration may be missed unless mouse embryos are examined relatively early $(10.5-12.5 \mathrm{dpc})$ in development, because early axon migration defects can in principle be corrected by remodeling and compensatory mechanisms by $15.5 \mathrm{dpc}$, as observed in Semaphorin 3A mouse mutants (White and Behar, 2000). In contrast to developmental gene expression-based assays, this immunohistochemical approach allows analysis of neuron development directly and makes no assumptions of what gene expression patterns may be the most important. Finally, processed embryos can be stored for over a year, thus preserving the experimental record.

After mutagenizing C57BL/6J male mice with ENU and mating these with C57BL/6J females, we randomly selected 40 first generation $\left(G_{1}\right)$ progeny males for additional breeding, bred each $\mathrm{G}_{1}$ male to five to seven of his daughters, and assayed the resulting $\mathrm{G}_{3}$ progeny (supplemental Fig. 2, available at www.jneurosci.org as supplemental material). A $\mathrm{G}_{1}$ male was considered to carry a mutation if multiple embryos in a litter and in several subsequent litters showed the same phenotype. We chose the C57BL/6J strain for these experiments, because its genomic sequence is available in the public domain and it performs well in many behavioral assays. Also, by maintaining a uniform genetic background, we are able to assess phenotypic variability immediately. Our confidence of the initial phenotypic presentation informed our selection of which mutants to pursue. In this manner, we identified one mutation that specifically disrupts facial nerve development, one that affects sensory neuron development and localization of motor neuron cell bodies, one that disrupts ventral exit of motor neuron axons from the neural tube, and four mutations with axon guidance deficits in the periphery (supplemental Table 1, available at www.jneurosci.org as supplemental material).

\section{Identification of a mutation with facial nerve deficits}

We were most interested in identifying new mutations that affected only one or a subset of cranial nerves and might model aspects of human craniofacial syndromes. We identified one such mutation, 7-1. In mice homozygous for mutation 7-1, the facial and acoustic nerves consistently show abnormal "sprouting" or "branching" in 10.5 dpc embryos (Fig. 1). In 12.5-13.5 dpc 7-1 homozygotes, the lower jaw is severely reduced, the head appears smaller, and blood is largely absent. (Fig. 1E,F). Genetic mapping determined that 7-1 is located on chromosome 15 between D15MIT280 at $24 \mathrm{Mb}$ and D15MIT111 at $32.2 \mathrm{Mb}$ within a region of conserved synteny to that in which the gene(s) responsible for the craniofacial and mental retardation deficits of human cri-du-chat syndrome reside (supplemental Table 1, available at www.jneurosci.org as supplemental material).

\section{Identification of a mutation with abnormal sensory ganglia development}

In the mouse, previous genetic screens have used obvious defects in head morphology at 8.5 and $10.5 \mathrm{dpc}$ to identify mutations required for dorsoventral patterning or telencephalic development (Kasarskis et al., 1998; Zoltewicz et al., 1999; Anderson, 2000; Eggenschwiler et al., 2001; Garcia-Garcia and Anderson, 2003). We also identified possible mutations that caused a variety of morphological defects. These included one mutation that caused severe deficits in cardiac development, two mutations that caused a dramatic overproliferation of the anterior CNS similar to that observed in presenilin 1, Casp9 (caspase 9), and Apaf1 (apoptosis protease-activating factor 1) mutants (Wong et al., 1997; Cecconi et al., 1998; Hakem et al., 1998; Kuida et al., 1998),
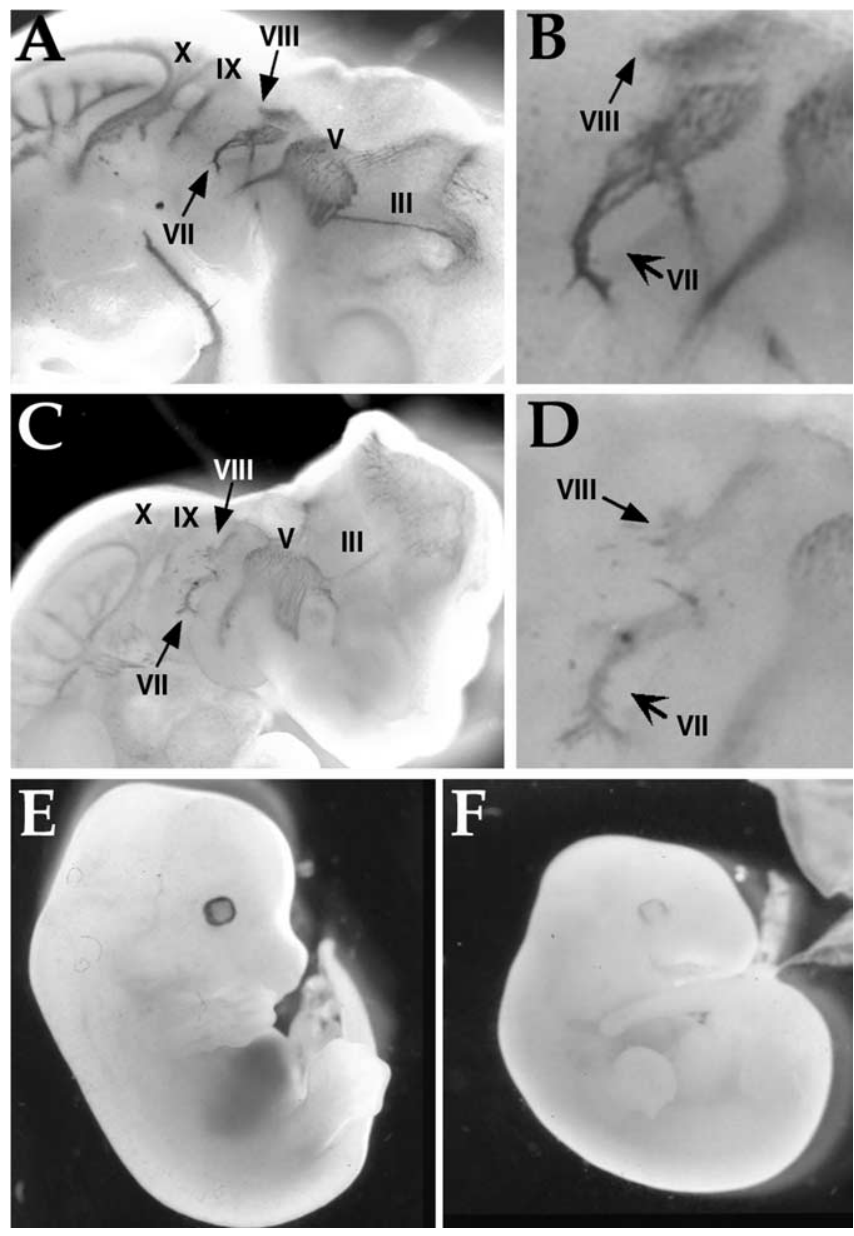

Figure 1. Embryos homozygous for the 7-1 mutation have facial nerve abnormalities. The facial nerve of normal $557 \mathrm{BL} / 6 \mathrm{~J} 10.5 \mathrm{dpc}$ embryos $(\boldsymbol{A}, \boldsymbol{B})$ is well fasciculated and travels as one smooth stream toward its targets. In contrast, the facial (VII) nerve in embryos homozygous for the 7-1 mutation $(\boldsymbol{C}, \boldsymbol{D})$ is reduced, and small branches jut off the nerve stem, giving it a rough "sprouty" appearance. Except for some minor sprouting, the apparent targeting of the acoustic nerve (VIII) to the otic vesicle appears mostly normal. The arrows indicate the processes of the facial and acoustic nerves that are affected in 7-1 mutants. Although the other cranial nerves appear normal and smoothly fasciculated in 7-1 mutants, a fringe of aberrantly migrating axons can be seen at the midbrain/hindbrain junction. Magnification: $A, C, 20 \times ; B, D, 80 \times$. At 12.5 $\mathrm{dpc}$, when compared with normal littermates $(\boldsymbol{E}), 7-1$ homozygotes $(\boldsymbol{F})$ show a reduced lower jaw, smaller rounded heads, and an apparent paucity of blood.

two mutations (17-2 and 26-1) with abnormal telencephalic development, and one (22-1) with deficits in neural tube closure. After analyzing neuronal development in these with antineurofilament staining, the telencephalic mutation 26-1 and the neural tube closure mutation 22-1 consistently showed abnormalities in several aspects of cranial nerve development (Fig. 2). Because exencephaly and neuronal deficits of presumptive 17-2 mutants was extremely variable even on a pure C57BL/6J background, we chose not to pursue this mutation further.

In the 22-1 mutation, overall embryonic morphology appears to be fairly normal except for defects in dorsal neural tube closure, which were more prevalent in the anterior of the embryo (Fig. 2C,D). Immunostaining of sections with antineurofilament antibody revealed that sensory neurons appeared to be largely missing (Fig. $3 B, D, E$ ), and some motor neuron cell bodies were observed outside of the ventral neural tube. Motor neuron identity of these ectopic neurons was confirmed by Kreisler/MafB expression (data not shown). The pairing of these two 
deficits has been previously observed in animals, in which the neural crest has been physically or genetically ablated. General dorsal-ventral patterning, however, as assessed by region-specific expression of sonic hedgehog (Shh), Islet1 (Isl1), and Math1 appeared normal (Fig. $3 H, K, Q$ ). Genetic mapping located 22-1 near D1MIT132 at $43.7 \pm 7 \mathrm{Mb}$ on chromosome 1 . Given that, aside from the neuronal defects seen in 22-1 homozygotes, 22-1 heterozygotes display a white belly spot and that 22-1 homozygotes also have a curly tail, it seemed likely that 22-1 might represent a mutation in the $\mathrm{Pax} 3$ gene located in this region (Mansouri and Gruss, 1998). Sequencing of Pax3 from 22-1 homozygotes identified an A-to-T transition that alters isoleucine at amino acid position 86 , conserved in the paired box of all known paired domain proteins, to an asparagine (Fig. 4A). Such a nonconservative change would be predicted to have dramatic consequences on Pax 3 function. Thus, the 22-1 phenotype is almost certainly caused by this mutation in Pax3. In the future, complementation analyses with existing Pax3 alleles can test whether this mutation is indeed responsible for the 22-1 phenotype and molecular biologic and phenotypic analyses can determine whether the 22-1 allele acts as a hypomorphic or null allele. Previously, mutations that cause amino acid substitutions in the paired box of the human PAX3 protein have been associated with the auditory-pigmentary type I Waardenburg syndrome (WS-I) (Fig. 4B) (Zlotogora et al., 1995; Fortin et al., 1997; Sotirova et al., 2000; Wollnik et al., 2003).

\section{Identification of a mutation that affects global ventral motor axon outgrowth}

Anti-neurofilament staining of embryos homozygous for mutation 26-1 revealed that, although the anterior telencephalon is absent, anterior-posterior patterning, as judged by the position of sensory ganglia, appeared somewhat normal up to the midbrain-hindbrain boundary and the optic cup was always present (Fig. 2E,F). From examination of whole-mount embryos, it was unclear whether motor neurons were entirely absent or whether they simply failed to extend their axons into the periphery. However, examination of anti-neurofilament-immunostained sections revealed that, along the entire spinal cord and hindbrain, motor neurons were present, but extended their axons primarily dorsally in a somewhat feathery, disorganized manner (Fig. $3 C, F)$. In contrast, normally most motor axons, with the exception of those of the dMNs, extend ventrally out of the neural tube into the periphery (Fig. $3 A$ ). This phenotype was remarkably penetrant, because no ventral motor axon extension was observed along the entire embryonic axis of 26-1 mutants. In addition, neural crest-derived sensory nerves are also markedly reduced, and neural tube closure does not occur. Disruptions in sonic hedgehog signaling have been shown to cause deficits in both anterior patterning and motor neuron specification (Ericson et al., 1995; Marigo et al., 1996). However, sonic hedgehog expression appeared normal in the notochord and floorplate of 26-1 homozygotes, and the presence of the motor neuron speci- fication marker Islet 1 in domains adjacent to the floorplate indicated that sonic hedgehog signaling-dependent motor neuron specification occurred normally (Fig. $3 I, L$ ). In contrast, motor neuron-specific expression of the MafB(Kreisler) motor neuron differentiation marker was not observed in $10.5 \mathrm{dpc}$ embryos. Because 26-1 homozygotes die shortly after $10.5 \mathrm{dpc}$, later events in neural development could not be assessed. The 26-1 mutation is situated on chromosome 9 near D9MIT151 at $121.5 \mathrm{Mb}$, a region in which no genes with known roles in motor neuron outgrowth or anterior patterning have been located. Thus, 26-1 probably affects a novel gene with important roles in anterior neural patterning, neural tube closure, and, most excitingly, the initial events governing motor neuron differentiation and/or ventral motor neuron axon extension.

\section{Mutations with deficits in general axon guidance}

Axonal pathfinding proceeds in a stepwise manner. Initially, axons fasciculate as they extend toward their first target. On reaching a choice point within their first target field, they reorient themselves and their growth cones turn toward their next target field. A variety of molecules, the majority of which identified to date are secreted or cell surface molecules, mediate the guidance toward a given target area and axon fasciculation. On reaching their final destination, axons defasciculate and synaptogenesis begins. Progress past the first choice point and toward the second target is a complex process that involves molecular cues that mark the choice point and the intrinsic ability of a neuron to reset itself and redirect its axon migration appropriately.

Despite the small size of this screen, we recovered representative mutations that affect axon fasciculation and choice point execution (Fig. 5). Progeny from male 8-1 showed defects in overall axon fasciculation (Fig. 5C,D). Similar abnormalities in axon fasciculation have been reported in animals homozygous for disruptions of the neuropilin/VEGF (vascular endothelial growth factor) and the Eph receptor/ephrin signaling pathways 

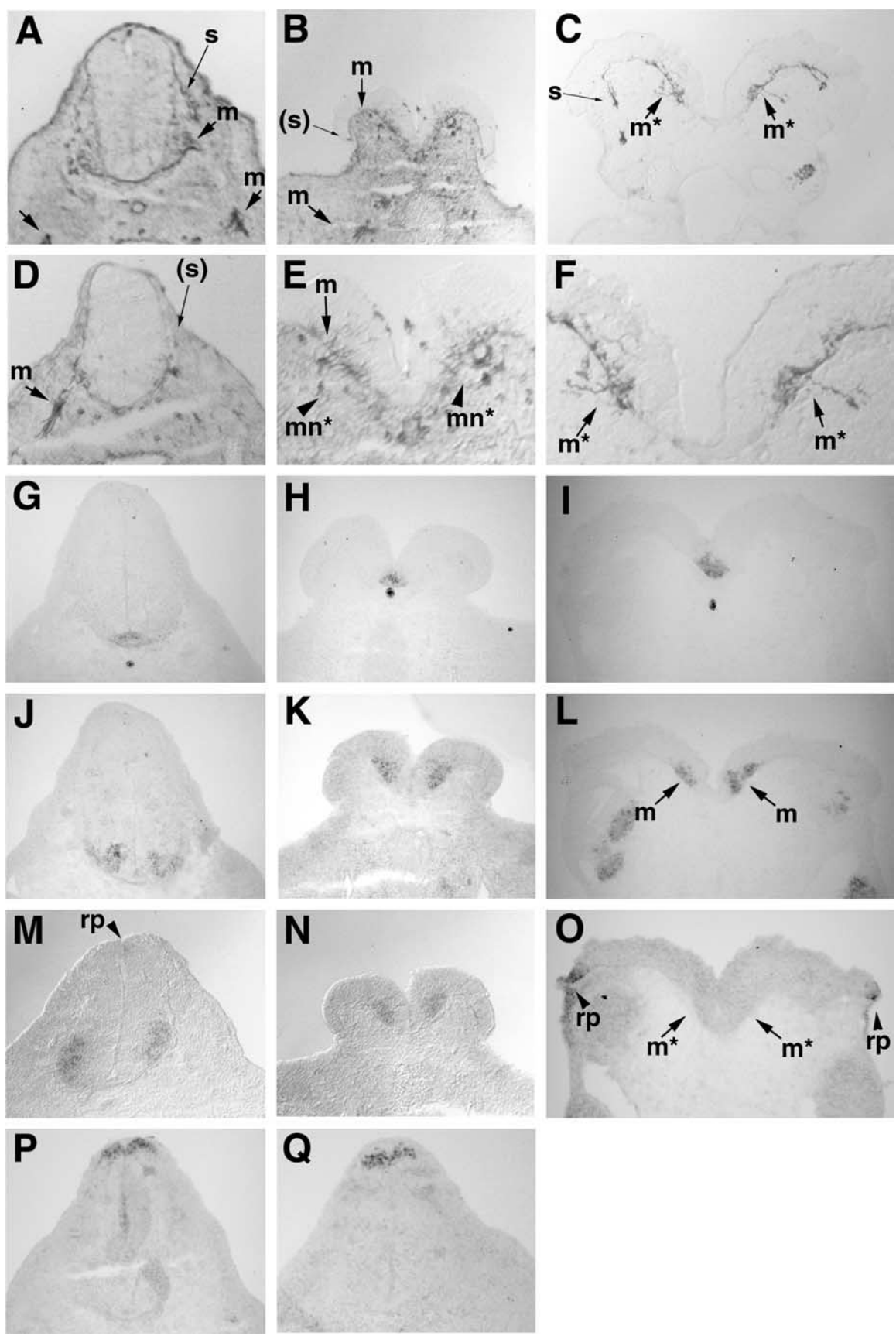

Figure 3. 22-1 and 26-1 mutants show specific defects in early sensory and motor neuron development. In normal $10.5 \mathrm{dpc}$ embryos $(\boldsymbol{A})$, immunostaining with anti-neurofilament antibody shows neural crest-derived sensory neurons ( $\mathrm{s}$ ) extending their axons from the dorsum ventrally along the spinal cord, and motor neuron axons (m) emerging from the ventral spinal cord and continuing to extend ventrally in a stream separate from that of sensory neuron axons. Immunostaining with anti-neurofilament antibody on sections from 22-1 (Pax3) homozygotes $(\boldsymbol{B}, \boldsymbol{D}, \boldsymbol{E})$ reveals that sensory neurons $[(\mathrm{s})]$ are missing and some motor neuron cell bodies ( $\mathrm{mn}^{*}$ ) are located ectopically outside of the neural tube. $\boldsymbol{B}$ and $\boldsymbol{E}$ show cross sections through a region of the neural tube that has failed to close. $\boldsymbol{D}$ shows a cross section through a region of the mutant 22-1 neural tube that has closed. Immunostaining of 26-1 homozygotes $(\boldsymbol{C}, \boldsymbol{F})$ reveals that motor neuron axons extend dorsally and appear generally thinner and disorganized. Sensory neurons are present but markedly reduced. The neural tube remains open along the entire anteriorposterior axis. Sonic hedgehog expression is observed in the notochord and floorplate of normal $(\boldsymbol{G}), 22-1(\boldsymbol{H})$, and 26-1 (I) embryos, and /slet1 expression is observed in the region adjacent to the floorplate in normal (J), 22-1 (K), and 26-1 (L) 10.5 dpc embryos. In contrast, Kreisler(MafB) is expressed normally in motor neurons from normal $(\boldsymbol{M})$ and 22-1 (N) homozygotes, but it is missing from motor neurons of 26-1 (0) homozygotes. Kreisler(MafB) expression can also be seen in the roofplate ( $r p$ ) of normal and 26-1 embryos. Arrows mark the region of /slet 1 expression in 26-1 mutants and the region in which Kreisler(MafB) expression is missing in 26-1 animals. Kreisler(MafB) expression can also be seen in the roofplate of normal embryos $(\boldsymbol{M})$ and in the region that would form the roofplate in 26-1 homozygotes (0). Math1 expression is indistinguishable between normal $(\boldsymbol{P})$ and 22-1 mutant embryos $(\mathbf{Q})$. Here, a region of the $22-1$ neural tube that is closed is shown.
(Kitsukawa et al., 1995; McBride and Ruiz, 1998; Wang et al., 1998; Adams et al., 1999; Gerety et al., 1999; Huynh-Do et al., 1999; Kawasaki et al., 1999; Helbling et al., 2000). Thus, one of these pathways may be affected here as well.

We also recovered one mutation, 25-3, that appears to affect axon targeting and possibly axonal redirection at the first choice point (Fig. 5E,F). Embryos homozygous for the 25-3 mutation appear to exhibit deficits in choice point execution. In $10.5 \mathrm{dpc} 25-3$ embryos, the axons of the cranial nerves appear to exit the neural tube and fasciculate appropriately. However, as these axons approach their presumptive first choice point, they appear to meander in a zigzagging manner before proceeding to their second target field. This is particularly apparent in the trajectory of the oculomotor nerve and in the additional branches seen for the facial nerve (Fig. 5F).

\section{Mutations with deficits in oculomotor neuron guidance}

In our screen, we recovered two mutations that affect the axonal projections of the oculomotor nerve. In embryos from male $3-4$, the axons of the oculomotor (III) nerve stream out from the neural tube in a detached and disorderly manner (Fig. $5 G, H)$. This could represent either a defect in specification or guidance of the oculomotor nerve, because no other nerves appear to be overtly affected at $10.5 \mathrm{dpc}$. Finally, in progeny from mouse $3-3$, the oculomotor nerve consistently showed delays in its migration toward its first target field (Fig. $5 I, J$ ). This may represent an extrinsic deficit in the target field or an intrinsic inability of the oculomotor nerve to respond to its guidance cues.

\section{Discussion}

Our screen is the first one in the mouse that has examined early neuronal development directly with immunohistochemical techniques. Other small-scale recessive screens have identified neurodevelopmental mouse mutations by screening neonates or $10.5 \mathrm{dpc}$ embryos for gross external morphological abnormalities or by examining expression of a neuron-specific LacZ reporter in transgenic embryos (Kasarskis et al., 1998; Zoltewicz et al., 1999; Herron et al., 2002; Kile et al., 2003; Zarbalis et al., 2004). Our immunohistochemical approach has the advantage that it can be performed on any strain without previous generation of transgenic animals and examines neurodevelopment directly.

The recovery of seven neurodevelop- 
A. Gly Cys Val Ser Lys Asn Leu Ala Arg 22-1 Pax3 GGT TGC GTC TCT AAG AAC CTG TGC AGG C57 Pax3 GGT TGC GTC TCT AAG ATC CTG TGC AGG Gly Cys Val Ser Lys Ile Leu Ala Arg

B.

22-1 Pax3 NQLGGVFING RPLPNHIRHK IVEMAHHGIR PCDISRQLRV SHGCVSKNLA RYNETĠSILP normal Pax3 NQLGGVFING RPLPNHIRHK IVEMAHHGIR PCDISRQLRV SHGCVSKILA RYNETGSILP paired domain NQLGG-E-NG RPLP---R-- IV-AH-G-R PC-ISR-L-V S-GCVSKIL- RY--TGSI-P

22-1 Pax3 GAIGGSKPRV TTPTVVKHIR TYKRENPGMF SWEIRDKLLK YAVCDRNTVP SVSSISRILR normal Pax3 GAIGGSKPRV TTPTVVKHIR TYKRENPGMF SWEIRDKLLK DAVCDRNTVP SVSSISRILR paired domain --IGGSKP-V -TP-V-K-I- -YK---P--F -WEIRD--L- ---C-----P SVSSI-R-LR

Figure 4. Identification of a point mutation in the Pax3 gene of 22-1 mutants. A, An A-to-T transition that alters isoleucine at amino acid 86 (which is conserved in the paired box of all known paired domain proteins) to an asparagine is found in the Pax3 gene of 22-1 mutants. $\boldsymbol{B}$, Amino acid sequence alignment of $\mathrm{Pax} 3$ protein from 22-1 mutants and normal mice. The light gray boxes indicate amino acids that are conserved among all known paired domain containing proteins. Dark gray boxes indicate amino acids that are altered in some cases of human Waardenburg syndrome type I (Vogan et al., 1993; Zlotogora et al., 1995; Fortin et al., 1997; Sotirova et al., 2000; Wollnik et al., 2003).

mental mutations after screening only $40 \mathrm{G}_{1}$ mice demonstrates that this strategy, if expanded, would be as productive as similar invertebrate genetic screens. Considering that the ENU dosage used should lead to identification of a recessive mutation in any given gene after screening $500-1500 \mathrm{G}_{1}$ animals, the mouse genome contains $\sim 25,000-30,000$ genes, and $\sim 20 \%$ of $\mathrm{G}_{1}$ mice carried neurodevelopmental mutations, $\sim 1-2 \%$ of randomly introduced recessive mutations should result in neurodevelopmental deficits scorable in 10.5 dpc embryos. Although $\mathrm{G}_{1}$ males carry mutations in multiple genes, successive outcrossing significantly reduces confounding effects of other mutations. Our results also predict that at least $1-2 \%$ of existing mouse mutations, whether generated by gene targeting or random mutagenesis, are likely to have early neurobiologic consequences. In the future, secondary screens, including other immunohistochemical assays, transgenic reporters, or behavioral assays, can assist in the additional classification of mutations. Thus, an expanded version of this screen would provide a valuable resource for the neurobiology community.

The mouse acts as an important intermediate for understanding human neurobiology. In this screen, we recovered two mutations that model human genetic diseases. One of these, mutation 7-1, models aspects of the human cri-du-chat deletion syndrome. Our identification of the 7-1 mutation, which is almost certainly caused by a mutation in a single gene, strongly suggests that loss of this one gene is responsible for the lower jaw deficits seen in some cri-du-chat patients. Cri-du-chat patients often exhibit difficulty swallowing and suckling, strabismus, and saliva control problems, which are likely caused by as-yet-undefined deficits in cranial nerve development. Thus, the 7-1 mutation will help elucidate specific cranial nerve deficits present in some cri-du-chat patients that heretofore may have been overshadowed by the more overwhelming symptoms (Church et al., 1995, 1997; Cornish and Munir, 1998; Mainardi et al., 2001).

Our identification of the I86N alteration in the Pax3 protein provides additional structure-function information for a protein with an already-established role in human type I and type III Waardenburg syndromes. In humans, WS-I is an auditory-pigmentary syndrome generally caused by heterozygous loss-offunction mutations in the PAX3 gene (Fig. 4B) (Vogan et al., 1993; Zlotogora et al., 1995; Fortin et al., 1997; Sotirova et al., 2000). Homozygosity or compound heterozygosity for PAX3
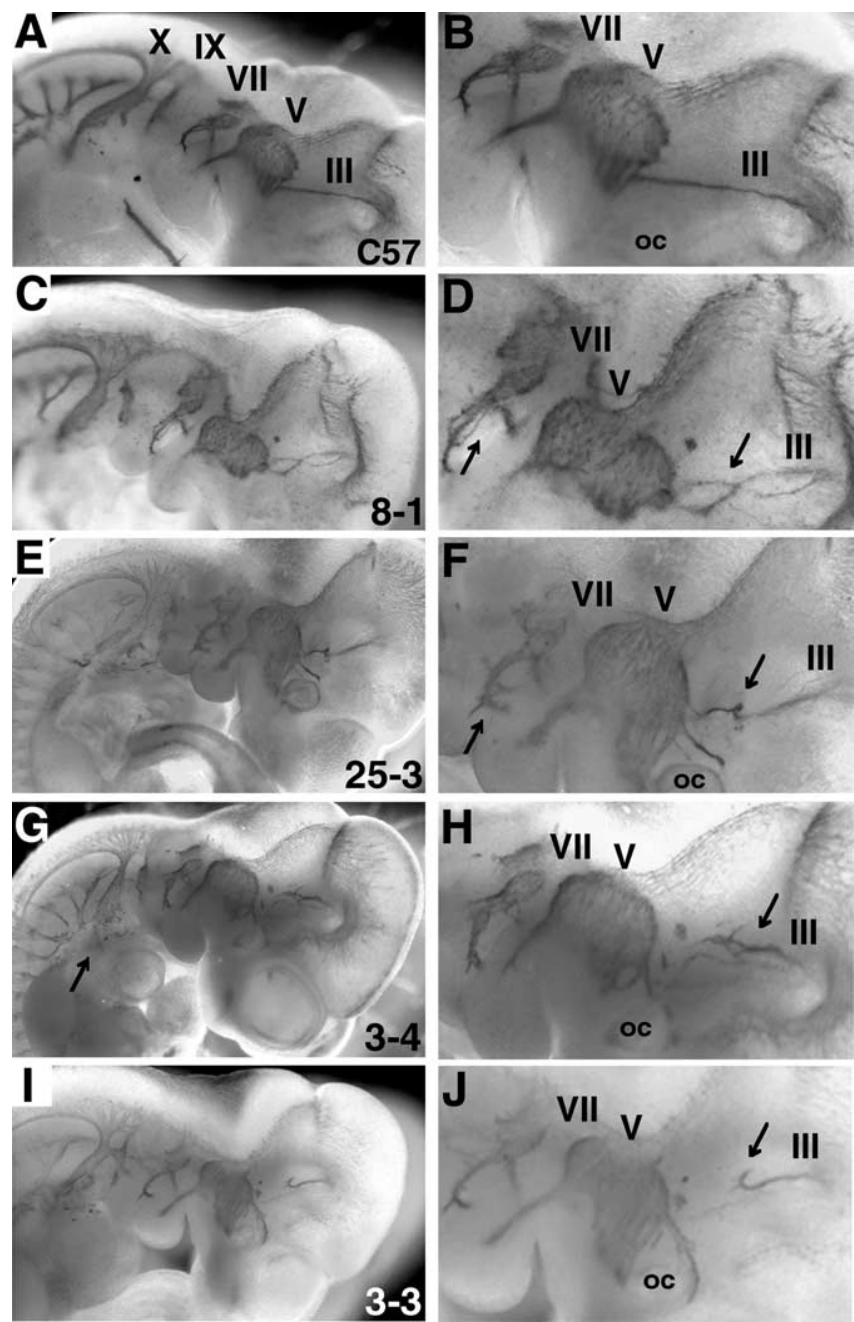

Figure 5. Recovery of mutations that cause distinct deficits in axon guidance. $\boldsymbol{A}$, Immunohistochemistry with the $2 \mathrm{H} 3$ anti-neurofilament antibody stains the cranial nerves in normal C57BL/6J 10.5 dpc embryos. $\boldsymbol{B}$, At a higher magnification, the consolidated origins, smooth fasciculation, and directed neurite extension can be clearly seen of the oculomotor (III), trigeminal (V), and facial (VII) nerves of $10.5 \mathrm{dpc}$ (57BL/6J embryos. C, In embryos homozygous for the 8-1 mutation, overall defasciculation of axons is observed and is particularly apparent in the extension of the oculomotor and facial nerves, which are marked by arrows, at a higher magnification (D). $\boldsymbol{E}, \boldsymbol{F}$, In 10.5 dpc embryos homozygous for the 25-3 mutation, nerves originate in their proper locations and appear to remain fasciculated. However, a "zigzag" can be observed as axons approach their first presumptive choice points. These deviations are indicated by arrows and are particularly apparent for the facial (VII) and oculomotor (III) nerves. G, $\boldsymbol{H}$, In mice carrying the 3-4 mutation, the oculomotor (III) nerve fibers, marked by an arrow, emerge from their site of origin in a disorganized manner. I, J, Embryos homozygous for the 3-3 mutations have oculomotor (III) nerves, shown by an arrow, that extend normally from their site of origin, but then seem to delay their axonal extension halfway to their presumptive first choice point. Magnification: $\boldsymbol{A}, \boldsymbol{C}, \boldsymbol{E}, \boldsymbol{G}, \boldsymbol{I}, 10 \times ; \boldsymbol{B}, \boldsymbol{D}, \boldsymbol{F}, \boldsymbol{H}, \boldsymbol{J}, 40 \times$. III, V, VII, VIII, IX, X, XII designate cranial nerves; oc, optic cup.

mutations has been documented in patients with Klein-Waardenburg syndrome (WS-III). On occasion, missense or specific deletion mutations in the paired domain of the PAX3 gene can cause WS-III (Fig. 4B) (Wollnik et al., 2003). Thus, additional analyses of the 22-1 phenotype will contribute further to our understanding of PAX3 structure and function in humans (Engelkamp and van Heyningen, 1996; Fortin et al., 1997).

The Shh signaling pathway has been shown to play essential roles in the anterior CNS patterning (Hooper and Scott, 2005), neuronal development (Roelink et al., 1994; Ericson et al., 1995), and guidance within the ventral neural tube (Charron et al., 
A Axon extension

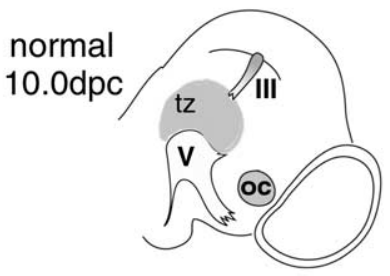

B Targeting

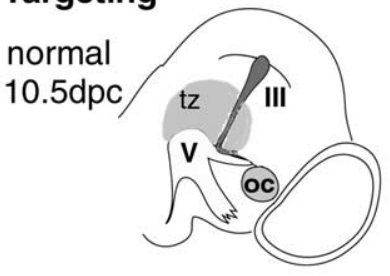

\section{Mutants}
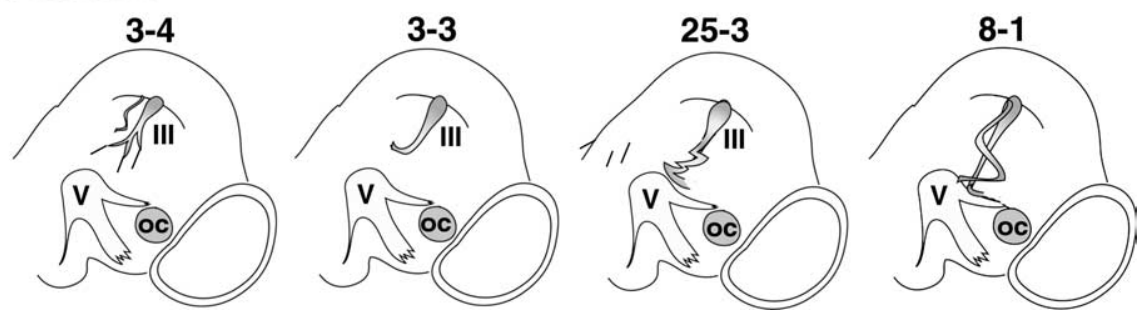

Figure 6. Effects of mutations on oculomotor (III) nerve pathfinding. A, A schematic diagram shows early axon extension of the oculomotor nerve (III) from the midbrain toward the trigeminal (V) nerve in $10.0 \mathrm{dpc}$ mouse embryos. The transition zone (tz) begins halfway between the midbrain and the trigeminal nerve root. Up to this point, oculomotor (III) axon extension appears to be independent of the factors present in the transition zone. $\boldsymbol{B}$, By $10.5 \mathrm{dpc}$, the axons of the oculomotor nerve have reached the trigeminal nerve and are extending toward the optic cup (oc). During this stage, oculomotor axon extension becomes dependent on factors present in the transition zone. $\boldsymbol{C}$, Schematic diagrams show the oculomotor deficits seen in the four axon guidance mutants recovered. The 3-4 and 3-3 mutations appear to affect initial axon extension of the oculomotor nerve in $10.5 \mathrm{dpc}$ embryos. In 3-4 mutants, multiple processes (rather than one smooth process) extend from the midbrain toward the trigeminal nerve. In 3-3 mutants, axon extension stalls halfway toward its first target. In 8-1 and 25-3 mutants, the oculomotor nerve axons extend toward the optic cup in a timely manner, but their appearance is abnormal. In 25-3 mutants, axonal fasciculation appears mostly normal. Axons begin to extend normally toward the trigeminal nerve. However, midway toward the trigeminal nerve, axons remain fasciculated but zigzag until they reach the trigeminal nerve and turn toward the optic cup. In 8-1 mutants, general defasciculation is observed.

2003). Thus, defective Shh signaling easily could account for the twin observations of deficits in anterior patterning and motor neuron development in 26-1 mutants. To our surprise, Shh signaling appeared normal in 26-1 mutants, but motor axons projected their axons dorsally rather than ventrally. At present, only two genes, the chemokine stromal cell-derived factor 1 (SDF1) (Cxcl12) and its receptor Cxcr4, have been shown to have specific roles in governing initial ventrally directed motor axon outgrowth (Lieberam et al., 2005). The 26-1 mutation is in neither of these genes. Although chemokines and their receptors have been shown to direct cell migration in the nervous system (Bagri et al., 2002; Lu et al., 2002; Stumm et al., 2003; Belmadani et al., 2005; Knaut et al., 2005; Miller and Tran, 2005; Sapede et al., 2005), so far none has been shown to affect telencephalic patterning. Nonetheless, it is attractive to speculate that $26-1$ affects a gene with a key role in directing motor axon outgrowth by affecting the SDF1(Cxcl12)-Cxcr4 signaling pathway.

Aside from the two patterning mutations described, all remaining neurodevelopmental mutations appeared morphologically indistinguishable from their normal littermates, and only immunohistochemical staining revealed axon guidance abnormalities. The $10.5 \mathrm{dpc}$ progeny from male 8 - 1 showed defects in overall axon fasciculation, but not in axonal convergence. Interestingly, in $13.5 \mathrm{dpc}$ progeny from male 8-1, striking vascular abnormalities were also seen. An increasing number of molecules important for axon guidance, such as the neuropilins, semaphorins, and Eph receptors/ephrins play key roles in angiogenesis as well (Kitsukawa et al., 1995; McBride and Ruiz, 1998; Wang et al., 1998; Adams et al., 1999; Gerety et al., 1999; Huynh-Do et al., 1999; Kawasaki et al., 1999; Helbling et al., 2000; Park et al., 2004;
Gu et al., 2005). Thus, it is likely, but remains to be explored, that these two phenotypes may be caused by the same mutation.

Mutation 25-3 causes axons to zigzag as they approach their first choice point and may affect reorienting of cranial nerves at their first choice point. Some molecular cues that direct axons to cross the vertebrate and invertebrate midline have been identified (Brose and Tessier-Lavigne, 2000), but we know almost nothing about those that act globally or in a regionspecific manner to redirect axon extension in the periphery. Thus, mutation 25-3 should provide a unique foothold toward understanding axon targeting and choice point selection in mammals.

Interestingly, we found that mutations could be categorized by their effects on the oculomotor nerve (Fig. 6). The oculomotor nerve originates in the ventral midbrain, initially extends its axons toward the trigeminal (V) nerve, and then reorients its projections toward the optic cup (Fig. 6). Our ability to identify mutations that affect the oculomotor nerve trajectory may be a consequence of its long, solo pioneering path from the midbrain to its target. During its progress, no other major neurons obscure its visibility or can provide compensatory guidance cues. Thus, it is both more visible and probably more vulnerable to mutations than other cranial nerves.

Whereas 8-1 mutants showed general fasciculation deficits in the oculomotor and other nerves, three other mutations had more precise and biologically informative deficits in oculomotor nerve guidance. Mutation 3-4, in which the initial projections of the oculomotor nerve originate from the midbrain in a diffuse manner, may reflect anomalies in early midbrain development or deficits in oculomotor nerve differentiation or fasciculation. The oculomotor nerve deficits in mutations 3-3 and 25-3 suggest that cues present halfway between the midbrain and trigeminal nerve play a key role in oculomotor nerve guidance. In mutation 3-3, axonal extension of the oculomotor nerve stalls halfway between the trigeminal nerve and the midbrain, at a time when the trigeminal nerve has already extended its upper branch toward the optic cup. In the 25-3 mutation, oculomotor axons begin to zigzag halfway between the midbrain and trigeminal nerve, at roughly the same point at which the nerve stalls in 3-3 mutants. Thus, it seems plausible that guidance occurs in two phases here. This "halfway" point may mark the beginning of a "transition zone" and represent an interface between sequentially acting cues that keep the oculomotor axons on the straight and narrow and ultimately allow it to extend to its target area. Given these intriguing results, identification and analyses of additional mutations with specific deficits in oculomotor nerve guidance may provide one of the most fruitful avenues for exploring region-specific axon guidance in the mouse.

The availability of mouse genome sequence and advances in molecular genetic techniques will facilitate identification of the affected genes and additional analysis of their biological functions. So, genetic complementation experiments can be expe- 
dited by the ever-increasing number of targeted mutations $(>2000)$ in the mouse, the availability of mutations generated by multiple large-scale gene-trapping efforts in embryonic stem cells, and the gene-driven screening of ENU-mutagenized embryonic stem cells or cryopreserved sperm to generate allelic series (Chen et al., 2000; Coghill et al., 2002). Meiotic recombination experiments can be augmented with region-specific deletions to refine critical intervals (Justice et al., 1997; You et al., 1997; Goodwin et al., 2001; Kile et al., 2003). Gene rescue experiments can be performed by generation of mice transgenic for bacterial artificial chromosomes, which can be elegantly modified using the Red/ET recombineering system, which uses the $\lambda$ $\operatorname{Red} \alpha / \operatorname{Red} \beta$ recombinase pair (Lee et al., 2001; Yu and Bradley, 2001; Testa et al., 2003; Valenzuela et al., 2003). Finally, with the advent of stem cell technologies and efforts toward neuronal regeneration, molecules that will be identified in genetic screens and our understanding of their function may ultimately lead to the ability to regenerate precisely any nerves damaged by accident or illness. The productivity of this small-scale screen and the information we have already obtained underscores the power of this approach. The future identification of the genes affected in the mutations identified here and the expansion of this screen and addition of other primary and secondary assays should prove tremendously productive and informative.

\section{References}

Adams RH, Wilkinson GA, Weiss C, Diella F, Gale NW, Deutsch U, Risau W, Klein R (1999) Roles of ephrinB ligands and EphB receptors in cardiovascular development: demarcation of arterial/venous domains, vascular morphogenesis, and sprouting angiogenesis. Genes Dev 13:295-306.

Anderson KV (2000) Finding the genes that direct mammalian development: ENU mutagenesis in the mouse. Trends Genet 16:99-102.

Bagri A, Gurney T, He X, Zou YR, Littman DR, Tessier-Lavigne M, Pleasure SJ (2002) The chemokine SDF1 regulates migration of dentate granule cells. Cell 129:4249-4260.

Belmadani A, Tran PB, Ren D, Assimacopoulos S, Grove EA, Miller RJ (2005) The chemokine stromal cell-derived factor-1 regulates the migration of sensory neuron progenitors. J Neurosci 25:3995-4003.

Briscoe J, Pierani A, Jessell TM, Ericson J (2000) A homeodomain protein code specifies progenitor cell identity and neuronal fate in the ventral neural tube. Cell 101:435-445.

Brose K, Tessier-Lavigne M (2000) Slit proteins: key regulators of axon guidance, axonal branching, and cell migration. Curr Opin Neurobiol 10:95-102.

Cecconi F, Alvarez-Bolado G, Meyer BI, Roth KA, Gruss P (1998) Apaf1 (CED-4 homolog) regulates programmed cell death in mammalian development. Cell 94:727-737.

Charron F, Stein E, Jeong J, McMahon AP, Tessier-Lavigne M (2003) The morphogen sonic hedgehog is an axonal chemoattractant that collaborates with netrin-1 in midline axon guidance. Cell 113:11-23.

Chen Y, Yee D, Dains K, Chatterjee A, Cavalcoli J, Schneider E, Om J, Woychik RP, Magnuson T (2000) Genotype-based screen for ENU-induced mutations in mouse embryonic stem cells. Nat Genet 24:314-317.

Church DM, Bengtsson U, Nielsen KV, Wasmuth JJ, Niebuhr E (1995) Molecular definition of deletions of different segments of distal $5 p$ that result in distinct phenotypic features. Am J Hum Genet 56:1162-1172.

Church DM, Yang J, Bocian M, Shiang R, Wasmuth JJ (1997) A highresolution physical and transcript map of the Cri du chat region of human chromosome 5p. Genome Res 7:787-801.

Coghill EL, Hugill A, Parkinson N, Davison C, Glenister P, Clements S, Hunter J, Cox RD, Brown SD (2002) A gene-driven approach to the identification of ENU mutants in the mouse. Nat Genet 30:255-256.

Cordes SP (2001) Molecular genetics of cranial nerve development in mouse. Nat Rev Neurosci 2:611-623.

Cordes SP (2005) N-Ethyl- $N$-nitrosourea mutagenesis: boarding the mouse mutant express. Microbiol Mol Biol Rev 69:426-439.

Cornish KM, Munir F (1998) Receptive and expressive language skills in children with cri-du-chat syndrome. J Commun Disord 31:73-80.

Dodd J, Morton SB, Karagogeos D, Yamamoto M, Jessell TM (1988) Spatial regulation of axonal glycoprotein expression on subsets of embryonic spinal neurons. Neuron 1:105-116.

Eggenschwiler JT, Espinoza E, Anderson KV (2001) Rab23 is an essential negative regulator of the mouse Sonic hedgehog signalling pathway. Nature 412:194-198.

Engelkamp D, van Heyningen V (1996) Transcription factors in disease. Curr Opin Genet Dev. 6:334-342.

Ericson J, Muhr J, Jessell TM, Edlund T (1995) Sonic hedgehog: a common signal for ventral patterning along the rostrocaudal axis of the neural tube. Int J Dev Biol 39:809-816.

Fortin AS, Underhill DA, Gros P (1997) Reciprocal effect of Waardenburg syndrome mutations on DNA binding by the Pax-3 paired domain and homeodomain. Hum Mol Genet 6:1781-1790.

Garcia-Garcia MJ, Anderson KV (2003) Essential role of glycosaminoglycans in Fgf signaling during mouse gastrulation. Cell 114:727-737.

Gerety SS, Wang HU, Chen ZF, Anderson DJ (1999) Symmetrical mutant phenotypes of the receptor EphB4 and its specific transmembrane ligand ephrin-B2 in cardiovascular development. Mol Cell 4:403-414.

Goodwin NC, Ishida Y, Hartford S, Wnek C, Bergstrom RA, Leder P, Schimenti JC (2001) DelBank: a mouse ES-cell resource for generating deletions. Nat Genet 28:310-311.

Gu C, Yoshida Y, Livet J, Reimert DV, Mann F, Merte J, Henderson CE, Jessell TM, Kolodkin AL, Ginty DD (2005) Semaphorin 3E and plexin-D1 control vascular pattern independently of neuropilins. Science 307:265-268.

Hakem R, Hakem A, Duncan GS, Henderson JT, Woo M, Soengas MS, Elia A, de la Pompa JL, Kagi D, Khoo W, Potter J, Yoshida R, Kaufman SA, Lowe SW, Penninger JM, Mak TW (1998) Differential requirement for caspase 9 in apoptotic pathways in vivo. Cell 94:339-352.

Helbling PM, Saulnier DM, Brandli AW (2000) The receptor tyrosine kinase EphB4 and ephrin-B ligands restrict angiogenic growth of embryonic veins in Xenopus laevis. Development 127:269-278.

Herron BJ, Lu W, Rao C, Liu S, Peters H, Bronson RT, Justice MJ, McDonald JD, Beier DR (2002) Efficient generation and mapping of recessive developmental mutations using ENU mutagenesis. Nat Genet 30:185-189.

Hooper JE, Scott MP (2005) Communicating with Hedgehogs. Nat Rev Mol Cell Biol 6:306-317.

Huynh-Do U, Stein E, Lane AA, Liu H, Cerretti DP, Daniel TO (1999) Surface densities of ephrin-B1 determine EphB1-coupled activation of cell attachment through alphavbeta3 and alpha5betal integrins. EMBO J 18:2165-2173.

Justice MJ, Zheng B, Woychik RP, Bradley A (1997) Using targeted large deletions and high-efficiency $\mathrm{N}$-ethyl- $\mathrm{N}$-nitrosourea mutagenesis for functional analyses of the mammalian genome. Methods 13:423-436.

Kasarskis A, Manova K, Anderson KV (1998) A phenotype-based screen for embryonic lethal mutations in the mouse. Proc Natl Acad Sci USA 95:7485-7490.

Kawasaki T, Kitsukawa T, Bekku Y, Matsuda Y, Sanbo M, Yagi T, Fujisawa H (1999) A requirement for neuropilin-1 in embryonic vessel formation. Development 126:4895-4902.

Kile BT, Hentges KE, Clark AT, Nakamura H, Salinger AP, Liu B, Box N, Stockton DW, Johnson RL, Behringer RR, Bradley A, Justice MJ (2003) Functional genetic analysis of mouse chromosome 11. Nature 425:81-86.

Kitsukawa T, Shimono A, Kawakami A, Kondoh H, Fujisawa H (1995) Overexpression of a membrane protein, neuropilin, in chimeric mice causes anomalies in the cardiovascular system, nervous system and limbs. Development 121:4309-4318.

Knaut H, Blader P, Strahle U, Schier AF (2005) Assembly of trigeminal sensory ganglia by chemokine signaling. Neuron 47:653-666.

Kuida K, Haydar TF, Kuan CY, Gu Y, Taya C, Karasuyama H, Su MS, Rakic P, Flavell RA (1998) Reduced apoptosis and cytochrome $c$-mediated caspase activation in mice lacking caspase 9. Cell 94:325-337.

Lee EC, Yu D, Martinez de Velasco J, Tessarollo L, Swing DA, Court DL, Jenkins NA, Copeland NG (2001) A highly efficient Escherichia colibased chromosome engineering system adapted for recombinogenic targeting and subcloning of BAC DNA. Genomics 73:56-65.

Leighton PA, Mitchell KJ, Goodrich LV, Lu X, Pinson K, Scherz P, Skarnes WC, Tessier-Lavigne M (2001) Defining brain wiring patterns and mechanisms through gene trapping in mice. Nature 410:174-179.

Lieberam I, Agalliu D, Nagasawa T, Ericson J, Jessell TM (2005) A cxcl12CXCR4 chemokine signaling pathway defines the initial trajectory of mammalian motor axons. Neuron 47:667-679. 
Lin JH, Saito T, Anderson DJ, Lance-Jones C, Jessell TM, Arber S (1998) Functionally related motor neuron pool and muscle sensory afferent subtypes defined by coordinate ETS gene expression. Cell 95:393-407.

Liu JP, Laufer E, Jessell TM (2001) Assigning the positional identity of spinal motor neurons: rostrocaudal patterning of Hox-c expression by FGFs, Gdf11, and retinoids. Neuron 32:997-1012.

Lu M, Grove EA, Miller RJ (2002) Abnormal development of the hippocampal dentate gyrus in mice lacking the CXCR4 chemokine receptor. Proc Natl Acad Sci USA 99:7090-7095.

Lumsden A, Keynes R (1989) Segmental patterns of neuronal development in the chick hindbrain. Nature 337:424-428.

Mainardi PC, Perfumo C, Cali A, Coucourde G, Pastore G, Cavani S, Zara F, Overhauser J, Pierluigi M, Bricarelli FD (2001) Clinical and molecular characterisation of 80 patients with 5p deletion: genotype-phenotype correlation. J Med Genet 38:151-158.

Mansouri A, Gruss P (1998) Pax3 and Pax7 are expressed in commissural neurons and restrict ventral neuronal identity in the spinal cord. Mech Dev 78:171-178.

Marigo V, Laufer E, Nelson CE, Riddle RD, Johnson RL, Tabin C (1996) Sonic hedgehog regulates patterning in early embryos. Biochem Soc Symp 62:51-60.

Mark M, Lufkin T, Vonesch JL, Ruberte E, Olivo JC, Dolle P, Gorry P, Lumsden A, Chambon P (1993) Two rhombomeres are altered in Hoxa-1 mutant mice. Development 119:319-338.

McBride JL, Ruiz JC (1998) Ephrin-A1 is expressed at sites of vascular development in the mouse. Mech Dev 77:201-204.

Miller RJ, Tran PB (2005) Chemokinetics. Neuron 47:621-623.

Mitchell KJ, Pinson KI, Kelly OG, Brennan J, Zupicich J, Scherz P, Leighton PA, Goodrich LV, Lu X, Avery BJ, Tate P, Dill K, Pangilinan E, Wakenight P, Tessier-Lavigne M, Skarnes WC (2001) Functional analysis of secreted and transmembrane proteins critical to mouse development. Nat Genet 28:241-249.

Park KW, Crouse D, Lee M, Karnik SK, Sorensen LK, Murphy KJ, Kuo CJ, Li DY (2004) The axonal attractant Netrin-1 is an angiogenic factor. Proc Natl Acad Sci USA 101:16210-16215.

Roelink H, Augsburger A, Heemskerk J, Korzh V, Norlin S, Ruiz i Altaba A, Tanabe Y, Placzek M, Edlund T, Jessell TM (1994) Floor plate and motor neuron induction by vhh-1, a vertebrate homolog of hedgehog expressed by the notochord. Cell 76:761-775.

Sapede D, Rossel M, Dambly-Chaudiere C, Ghysen A (2005) Role of SDF1 chemokine in the development of lateral line efferent and facial motor neurons. Proc Natl Acad Sci USA 102:1714-1718.

Sotirova VN, Rezaie TM, Khoshsorour MM, Sarfarazi M (2000) Identification of a novel mutation in the paired domain of PAX3 in an Iranian family with waardenburg syndrome type I. Ophthalmic Genet 21:25-28.

Stumm RK, Zhou C, Ara T, Lazarini F, Dubois-Dalcq M, Nagasawa T, Hollt
V, Schulz S (2003) CXCR4 regulates interneuron migration in the developing neocortex. J Neurosci 23:5123-5130.

Takahashi JS, Pinto LH, Vitaterna MH (1994) Forward and reverse genetic approaches to behavior in the mouse. Science 264:1724-1733.

Testa G, Zhang Y, Vintersten K, Benes V, Pijnappel WW, Chambers I, Smith AJ, Smith AG, Stewart AF (2003) Engineering the mouse genome with bacterial artificial chromosomes to create multipurpose alleles. Nat Biotechnol 21:443-447.

Tsuchida T, Ensini M, Morton SB, Baldassare M, Edlund T, Jessell TM, Pfaff SL (1994) Topographic organization of embryonic motor neurons defined by expression of LIM homeobox genes. Cell 79:935-943.

Valenzuela DM, Murphy AJ, Frendewey D, Gale NW, Economides AN, Auerbach W, Poueymirou WT, Adams NC, Rojas J, Yasenchak J, Chernomorsky R, Boucher M, Elsasser AL, Esau L, Zheng J, Griffiths JA, Wang X, Su H, Xue Y, Dominguez MG, et al. (2003) High-throughput engineering of the mouse genome coupled with high-resolution expression analysis. Nat Biotechnol. 21:652-659.

Wang HU, Chen ZF, Anderson DJ (1998) Molecular distinction and angiogenic interaction between embryonic arteries and veins revealed by ephrin-B2 and its receptor Eph-B4. Cell 93:741-753.

White FA, Behar O (2000) The development and subsequent elimination of aberrant peripheral axon projections in Semaphorin3A null mutant mice. Dev Biol 225:79-86.

Wilkie AO, Morriss-Kay GM (2001) Genetics of craniofacial development and malformation. Nat Rev Genet 2:458-468.

Wollnik B, Tukel T, Uyguner O, Ghanbari A, Kayserili H, Emiroglu M, Yuksel-Apak M (2003) Homozygous and heterozygous inheritance of PAX3 mutations causes different types of Waardenburg syndrome. Am J Med Genet 122A:42-45

Wong PC, Zheng H, Chen H, Becher MW, Sirinathsinghji DJ, Trumbauer ME, Chen HY, Price DL, Van der Ploeg LH, Sisodia SS (1997) Presenilin 1 is required for Notch 1 and DII1 expression in the paraxial mesoderm. Nature 387:288-292.

You Y, Bergstrom R, Klemm M, Lederman B, Nelson H, Ticknor C, Jaenisch R, Schimenti J (1997) Chromosomal deletion complexes in mice by radiation of embryonic stem cells. Nat Genet 15:285-288.

Yu Y, Bradley A (2001) Engineering chromosomal rearrangements in mice. Nat Rev Genet 2:780-790.

Zarbalis K, May SR, Shen Y, Ekker M, Rubenstein JL, Peterson AS (2004) A focused and efficient genetic screening strategy in the mouse: identification of mutations that disrupt cortical development. PLoS Biol 2:E219.

Zlotogora J, Lerer I, Bar-David S, Ergaz Z, Abeliovich D (1995) Homozygosity for Waardenburg syndrome. Am J Hum Genet 56:1173-1178.

Zoltewicz JS, Plummer NW, Lin MI, Peterson AS (1999) oto is a homeotic locus with a role in anteroposterior development that is partially redundant with lim1. Development 126:5085-5095. 